\title{
Linking glacier annual mass balance and glacier albedo retrieved from MODIS data
}

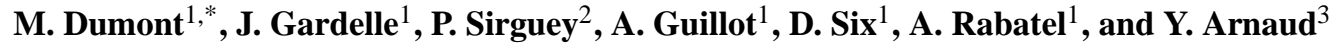 \\ ${ }^{1}$ Université Joseph Fourier, Grenoble I/CNRS, LGGE - UMR5183, Grenoble, France \\ ${ }^{2}$ School of Surveying, University of Otago, P.O. Box 56, Dunedin, New Zealand \\ ${ }^{3}$ Université Joseph Fourier/IRD/CNRS/Grenoble INP, LTHE - UMR5564, Grenoble, France \\ *now at: Météo France/CRNS, CNRM-GAME - URA1357, CEN, Grenoble, France
}

Correspondence to: M. Dumont (marie.dumont@meteo.fr)

Received: 31 May 2012 - Published in The Cryosphere Discuss.: 10 July 2012

Revised: 29 October 2012 - Accepted: 25 November 2012 - Published: 19 December 2012

\begin{abstract}
Albedo is one of the variables controlling the mass balance of temperate glaciers. Multispectral imagers, such as MODerate Imaging Spectroradiometer (MODIS) on board the TERRA and AQUA satellites, provide a means to monitor glacier surface albedo. In this study, different methods to retrieve broadband glacier surface albedo from MODIS data are compared. The effect of multiple reflections due to the rugged topography and of the anisotropic reflection of snow and ice are particularly investigated. The methods are tested on the Saint Sorlin Glacier (Grandes Rousses area, French Alps). The accuracy of the retrieved albedo is estimated using both field measurements, at two automatic weather stations located on the glacier, and albedo values derived from terrestrial photographs. For summers 2008 and 2009, the root mean square deviation (RMSD) between field measurements and the broadband albedo retrieved from MODIS data at $250 \mathrm{~m}$ spatial resolution was found to be 0.052 or about $10 \%$ relative error. The RMSD estimated for the MOD10 daily albedo product is about three times higher. One decade (2000-2009) of MODIS data were then processed to create a time series of albedo maps of Saint Sorlin Glacier during the ablation season. The annual mass balance of Saint Sorlin Glacier was compared with the minimum albedo value (average over the whole glacier surface) observed with MODIS during the ablation season. A strong linear correlation exists between the two variables. Furthermore, the date when the average albedo of the whole glacier reaches a minimum closely corresponds to the period when the snow line is located at its highest elevation, thus when the snow line is a good indicator of the glacier equilibrium line. This indi-
\end{abstract}

cates that this strong correlation results from the fact that the minimal average albedo values of the glacier contains considerable information regarding the relative share of areal surfaces between the ablation zone (i.e. ice with generally low albedo values) and the accumulation zone (i.e. snow with a relatively high albedo). As a consequence, the monitoring of the glacier surface albedo using MODIS data can provide a useful means to evaluate the interannual variability of the glacier mass balance. Finally, the albedo in the ablation area of Saint Sorlin Glacier does not exhibit any decreasing trend over the study period, contrasting with the results obtained on Morteratsch Glacier in the Swiss Alps.

\section{Introduction}

The surface albedo of glaciers, also referred to as the bihemispherical broadband albedo (Schaepman-Strub et al., 2006) is defined as the reflected fraction of the incoming solar radiation. It largely governs the surface energy balance and thus the mass balance of temperate glaciers (Hock, 2005; Sicart et al., 2008; Six et al., 2009). During the ablation season, large temporal and spatial variations of the albedo occur that directly affect the amount of energy effectively absorbed by a glacier (Warren, 1982; Hock, 2005). The crucial importance of the albedo on the energy budget of a glacier in turn affects its mass balance. However, obtaining accurate and systematic ground measurements of this parameter throughout a glacier surface, and over extended periods of time, remains challenging. Towards this goal, remote sensing 
technologies have proven useful in allowing such variations to be monitored both spatially and temporally (Dozier et al., 2009).

Multiple algorithms have been developed to estimate the albedo of snow and ice surfaces from visible and near infrared (NIR) space borne imagery. For example, data from Landsat Thematic Mapper (TM) have been used to derive broadband glacier albedo in Switzerland (Knap et al., 1999a,b) and in Sweden (Klok et al., 2003). Still in the context of snow and ice targets, Greuell and Oerlemans (2004) proposed a set of empirical equations for several sensors (i.e. Landsat TM, Advanced Very High Resolution Radiometer (AVHRR), MODerate Imaging Spectroradiometer (MODIS), and Multi-angle Imaging SpectroRadiometer (MISR)) to convert measurements of narrowband albedo into estimates of broadband albedo. Many studies have since focused on the potential offered by the MODIS instrument to retrieve snow and ice albedo (e.g. Liang et al., 2005; Stroeve et al., 2006; Tedesco and Kokhanovsky, 2007; Zege et al., 2011), sometimes in conjunction with estimates of the snow grain size (Lyapustin et al., 2009; Painter et al., 2009; Zege et al., 2011).

However, multiple sources of uncertainties can affect the accuracy of albedo retrieval methods, particularly in mountainous terrain. We identify the main difficulties as being those associated with (i) the anisotropic reflection of snow and ic;, (ii) the method of conversion from narrowband albedo to broadband albedo; (iii) the effects of the atmosphere, clouds, and topography on the radiative budget of the surface; and (iv) the errors associated with image geolocation and terrain modelling. Indeed, the latter propagates to the computation of topographical derivatives (e.g. slope, aspect), which in turn affects (i) and (iii) by compromising the accurate representation of the illumination and viewing geometries.

In addition to the difficulty of estimating albedo from remote sensing data, the validation of retrieval methods is often complicated by (i) the scale differences between ground measurements and satellite data, and (ii) the effects of the topography on the illumination and, therefore, on the measured radiance. Thus, most studies presented above and involving MODIS have relied on measurements of albedo obtained on relatively flat and homogeneous surfaces for the design and assessment of their method.

In the context of monitoring snow covered areas in mountainous terrain, Sirguey et al. (2009) proposed and assessed a method to routinely map sub-pixel snow fraction at $250 \mathrm{~m}$ spatial resolution with MODIS. By implementing a comprehensive correction of the atmospheric and topographic effects, the method allowed the ground spectral reflectance of snow and ice to be estimated. This method was since adapted to retrieve broadband albedo from terrestrial photography while taking into account the snow and ice bidirectional reflectance distribution function (BRDF) (Dumont et al., 2011).
This study reports on a new method based on the work of Sirguey et al. (2009) and Dumont et al. (2011) to retrieve broadband albedo of ice and snow surfaces from MODIS. The latter is particularly adapted to mountainous environments as it allows mapping the albedo with a spatial resolution of $250 \mathrm{~m}$. The MODIS sensor onboard the TERRA platform provides daily measurements of radiance at the top of the atmosphere (TOA) in the visible (VIS), near-infrared (NIR), and short wave infrared (SWIR) wavelengths. Despite its relatively coarse spatial resolution (250 to $500 \mathrm{~m}$ for the seven spectral bands used in this study), MODIS's spectral resolution and high temporal resolution make it a prime candidate to monitor the surface albedo of glaciers.

The glacier surface albedo is closely related to its mass balance since it constrains its surface energy balance (Six et al., 2009). Several methods have been developed to characterise the relationship between albedo and mass balance variations (e.g. Greuell et al., 2007). Alternative methods based on remotely sensed data have also been developed to estimate the variations of mass balance from those of the equilibrium line altitude (ELA), namely the line of null mass balance which separate the ablation zone (ice) from the accumulation zone (snow) at the end of the ablation season (Rabatel et al., 2005, 2008). Both areas have greatly contrasting albedo. Consequently, it is hypothesised that the albedo of the glacier surface at the end of the ablation season may contain a valuable signal related to the annual mass balance. In proposing and validating a method to retrieve glacier albedo from MODIS, this study aims at characterizing further the relationship between the albedo measured at the end of the ablation season from MODIS data, the annual mass balance of a glacier and the ELA.

Section 2 briefly describes the validation site. Definitions and details on the retrieval method are given in Sect. 3. Section 4 presents results obtained on Saint Sorlin Glacier (Grandes Rousses area, France) and comparisons with broadband albedo obtained from ground measurements and terrestrial photographs. Sources of error are discussed in Sect. 4. Section 5 presents the first results obtained on Saint Sorlin Glacier while applying the method over the 2000-2009 period and comparing albedo with mass balance data. This section characterises the relationship between the annual mass balance of the glacier, its albedo and the ELA.

\section{Data and study site}

\subsection{Saint Sorlin Glacier}

Located at $45.10^{\circ} \mathrm{N}$ and $6.10^{\circ} \mathrm{E}$ in the Western Alps of France (Grandes Rousses area), Saint Sorlin Glacier covers $3 \mathrm{~km}^{2}$ (Fig. 1). The glacier extends from nearly $3500 \mathrm{~m}$ a.s.l. at Etendard Peak to around $2700 \mathrm{~m}$ a.s.l at its terminus. Its mass balance has been monitored by the Laboratoire de Glaciologie et de Géophysique de l'Environnement (LGGE, 


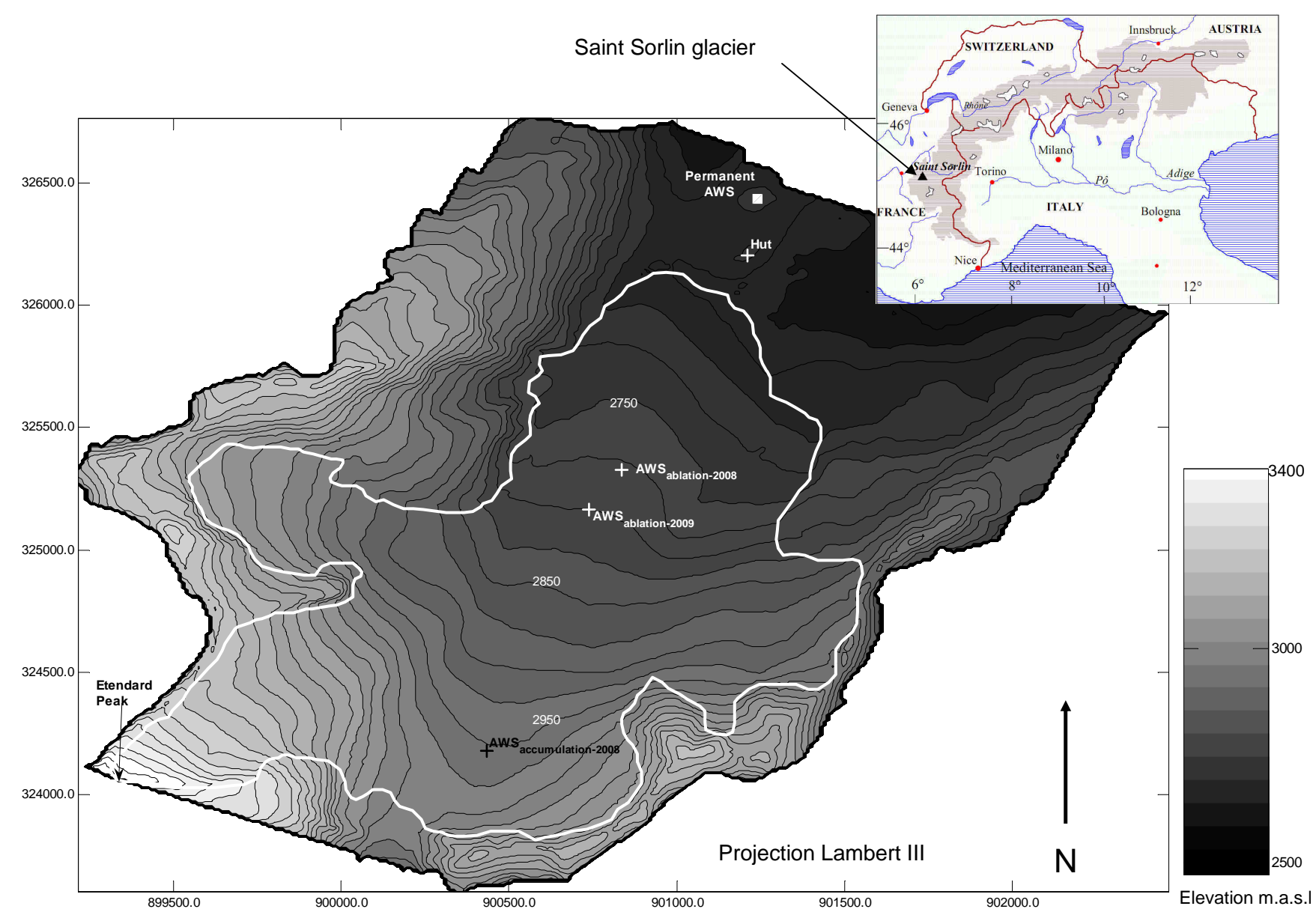

Fig. 1. Map of Saint Sorlin Glacier. Location of the AWS used for validation during summer 2008 and summer 2009 are indicated on the glacier. The cameras take photographs from the hut. Etendard peak is also indicated.

Grenoble, France) since 1957 (Vincent, 2002). The mean equilibrium line altitude (ELA) is around $2950 \mathrm{~m}$ a.s.l. Much information about mass balance measurements at this site can be found at http://www-lgge.ujf-grenoble.fr/ServiceObs.

A permanent automatic weather station (AWS) set on the moraine (2700 m a.s.l, see location in Fig. 1) has recorded half-hourly data since 2005. Measurements of air temperature and relative humidity are used to compute the solar irradiance as described in Sect. 3.

Finally, irradiance modelling and anisotropy corrections demand that accurate terrain geometry be modelled (Stroeve et al., 2006). For that reason, we used the Global Digital Elevation Model (GDEM) generated at $30 \mathrm{~m}$ spatial resolution from stereo imagery acquired with the Advanced Spaceborne Thermal Emission and Reflection Radiometer (ASTER) (http://asterweb.jpl.nasa.gov/gdem.asp).The estimated planimetric accuracy of the GDEM is about $\pm 30 \mathrm{~m}$ (Zhao et al., 2011).

\subsection{Ground measurements}

To estimate the accuracy of the maps of glacier albedo retrieved from MODIS, additional AWSs were set on the glacier during the ablation season: two stations (one in the ablation area and the other located in the accumulation zone) during summer 2008 and one station during summer 2009 in the ablation zone. Locations of these temporary stations are indicated in Fig. 1.

These temporary stations were equipped with a net radiometer Kipp and Zonen CNR1. The two pyranometers facing upward and downward, respectively, were used to measure the incident and reflected shortwave radiation (305-2800 nm) with a 15 min time interval. The ratio of both quantities allowed the bi-hemisperical albedo of the surface to be estimated. Considering a possible tilt of the instrument with respect to the surface of the glacier and the intrinsic accuracy of the sensor in both directions $( \pm 3 \%$ in terms of Root Mean Squared Error (RMSE), Six et al., 2009), the expected accuracy of the measured albedo value is $\pm 10 \%$ (RMSE) (Kipp and Zonen, 2009). The slope of the surface 
below the sensor is relatively small, about $5^{\circ}$. The footprint of the device is about $300 \mathrm{~m}^{2}$ (the instrument is about $1 \mathrm{~m}$ above the surface) (Kipp and Zonen, 2009).

\subsection{Terrestrial photography}

As described in Dumont et al. (2011), two digital cameras, one visible and one near-infrared, captured automatic photographs of the glacier three times a day which were used to compute maps of glacier broadband albedo at $10 \mathrm{~m}$ spatial resolution. It was shown that the accuracy of the final broadband albedo retrieved from terrestrial photography is $\pm 10 \%$ and compared to the inherent accuracy of the albedo derived from the net radiometer (Dumont et al., 2011). These maps were used to evaluate the method of albedo retrieval from MODIS data.

\subsection{MODIS data}

This study relied on MODIS/TERRA Level 1B radiances available at $\mathrm{http}: / /$ ladsweb.nascom.nasa.gov. These products give calibrated radiances at the top of the atmosphere (TOA) at $250 \mathrm{~m}$ spatial resolution (bands 1 and 2) and $500 \mathrm{~m}$ resolution (bands 3 to 7). Information on the viewing and incident geometry are also provided. Tables 1 and 2 provide a more comprehensive description of these products. Images were chosen so that the local time of the acquisition was approximately matching that of terrestrial photographs to allow the comparison between the maps of albedo retrieved from MODIS data and those derived from terrestrial photographs. Thirteen images were processed over the summer 2008, and twenty one images over the summer 2009.

MODIS daily snow products, MOD10A1 processed by the National Snow and Ice Data Center (Stroeve et al., 2006; Hall et al., 2007) also provide daily estimates of the albedo of snow surfaces at $500 \mathrm{~m}$ spatial resolution. They are used in our study for comparison with the albedo values produced using the retrieval method described in the next section. However, it should be noted that broadband albedo estimates from this data product correspond to directional-hemispheric reflectance (Klein and Stroeve, 2002). By considering irradiance from a collimated source only, this variable departs in its definition from the bolometric albedo being estimated in this study which can be referred to as the bi-hemispherical reflectance (Schaepman-Strub et al., 2006; Dumont et al., 2011).

\section{Retrieval method}

This section gives first a brief description of the processing of MODIS data to retrieve subpixel snow cover fraction in mountainous terrain (Sirguey et al., 2009) and then outlines the developments performed to retrieve broadband albedo.
Table 1. Description of the MODIS products used in this study.

\begin{tabular}{ll}
\hline Product name & Description \\
\hline MOD02QKM & $\begin{array}{l}\text { Reflectance at the top of the atmosphere, } \\
\text { for bands 1 and 2, at 250 m } \\
\text { Reflectance at the top of the atmosphere, } \\
\text { for bands 3 to 7, at 500 m }\end{array}$ \\
MOD02HKM & $\begin{array}{l}\text { Reflectance at the top of the atmosphere, } \\
\text { for bands 8 to 36, at 1 km } \\
\text { Geolocation, geometry and topography parameters, } \\
\text { such as solar and sensor azimuths and zeniths } \\
\text { Daily snow cover (albedo, lake ice, } \\
\text { snow cover) L3 500 m grid }\end{array}$ \\
\hline
\end{tabular}

Table 2. Description of the seven spectral bands of MODIS images used in this study.

\begin{tabular}{rr}
\hline Band & Band width (nm) \\
\hline 1 & $620-670$ \\
2 & $841-876$ \\
3 & $459-479$ \\
4 & $545-565$ \\
5 & $1230-1250$ \\
6 & $1628-1652$ \\
7 & $2105-2155$ \\
\hline
\end{tabular}

\subsection{Retrieving subpixel snow cover and hemispherical-conical reflectance}

The method used to map the snow and ice surfaces at subpixel level is extensively described in Sirguey et al. (2009). MODIS images are first reprojected and resampled. A multispectral fusion is applied between MOD02HKM $(500 \mathrm{~m}$, bands 3 to 7) and MOD02QKM (bands 1 and 2) data to produce images with seven synthetic spectral bands at $250 \mathrm{~m}$ spatial resolution (Sirguey et al., 2008). The Digital Number of each pixel is then converted into spectral conichemispherical reflectance (Schaepman-Strub et al., 2006) using atmospheric and topographic corrections from Bird and Riordan (1986) and Sirguey (2009). Maps of fractional snow cover are then calculated using linear spectral mixture algorithm whose accuracy was assessed using concomitant ASTER data (Sirguey et al., 2009).

\subsection{Retrieving broadband albedo}

In addition to the maps of fractional snow and ice cover, the method described above enable the radiance at ground level to be estimated for for each spectral band accounting for atmospheric effects and multiple reflections occurring in rugged terrain. Five bands are used in total in the retrieval method for albedo described below. The method is applied only to pixels identified as snow (i.e. containing more than $50 \%$ of snow). 


\subsubsection{From radiance to directional-hemispherical reflectance}

From the description provided by Dumont et al. (2011), it is possible to relate the directional-hemispherical reflectance, $\alpha$, hereafter called spectral albedo, to the radiance measured by MODIS, $L_{\text {MODIS }}$, by accounting for the anisotropy factor $R\left(\tilde{\theta}_{\mathrm{s}}, \tilde{\theta}_{\mathrm{v}}, \tilde{\phi}_{\mathrm{v}}, \lambda_{\mathrm{c}}\right)$, as follow

$\alpha\left(\tilde{\theta_{\mathrm{v}}}, \lambda_{\mathrm{c}}\right)=\frac{\pi L_{\mathrm{MODIS}}\left(\tilde{\theta}_{\mathrm{v}}, \tilde{\phi}_{\mathrm{v}}, \lambda_{\mathrm{c}}\right)}{E_{\mathrm{s}}\left(\lambda_{\mathrm{c}}\right) \cos \tilde{\theta}_{\mathrm{s}} R\left(\tilde{\theta_{\mathrm{v}}}, \tilde{\theta}_{\mathrm{s}}, \tilde{\phi}_{\mathrm{v}}, \lambda_{\mathrm{c}}\right)+E_{\mathrm{diff}}\left(\lambda_{\mathrm{c}}\right)}$

where $\tilde{\theta}_{\mathrm{v}}$ and $\tilde{\phi}_{\mathrm{v}}$, are, the viewing zenith and azimuth angle, respectively, expressed in the reference frame attached to the pixel of the glacier and aligned with the azimuth of the sun. $E_{\mathrm{s}}(\lambda)$ and $E_{\text {diff }}\left(\lambda_{\mathrm{c}}\right)$ are the direct and diffuse solar irradiances at ground level, respectively. $E_{\mathrm{S}}$ is inferred from a clear sky single layer atmospheric model (Bird and Riordan, 1986). $E_{\text {diff }}$ is derived using the same atmospheric model together with an iterative method to account for the contribution of the neighbouring slopes to the diffuse irradiance. This is described in more details in Dumont et al. (2011) and Sirguey (2009). $\alpha(\theta, \lambda)$ is the spectral albedo of the pixel. $L_{\text {MODIS }}\left(\tilde{\theta}_{\mathrm{v}}, \tilde{\phi}_{\mathrm{v}}, \lambda_{\mathrm{c}}\right)$ is the corrected MODIS radiance in the spectral band centred at $\lambda_{\mathrm{c}}$.

The anisotropy factor of snow and ice surfaces, $R\left(\tilde{\theta_{\mathrm{v}}}, \tilde{\theta}_{\mathrm{s}}, \tilde{\phi}_{\mathrm{v}}, \lambda_{\mathrm{c}}\right)$, was estimated using measurements of the BRDF obtained over snow and ice with a spectrogonioradiometer as explained in Dumont et al. (2010).

\subsubsection{From directional-hemispherical reflectance to broadband albedo}

The broadband albedo is inferred from the spectral albedo derived from five MODIS bands and using Look-Up-Tables (LUTs) generated with DISORT (Stamnes et al., 1988). The methodology is the same as the one described in Dumont et al. (2011). One LUT was produced for each of the two main classes of targets, namely ice and snow. The LUTs gather spectral albedo values simulated using DISORT when varying the snow specific surface area (SSA) (Domine et al., 2007), the soot content and the incident zenith angle. The SSA is inversely proportional to the optical radius of the snow grains and is defined as the ratio of the entire surface of the snow grains to the mass of the snow sample. Table 3 provides details about the varying parameters used to create both LUTs.

It becomes then possible to quantify the departure between the measured spectral albedo and each theoretical spectrum stored in the LUT. In turn, this provides a means to infer a full spectrum based on discrete spectral albedo measurements.

The computation follows the steps outlined below:
1. Using the DISORT LUTs, the values of SSA and soot content that minimise the spectral distance below are found

$d_{\mathrm{VIS}}=\sqrt{\frac{1}{3} \sum_{i=(1,2,4)}\left(\alpha_{\mathrm{MODIS}}\left(\lambda_{i}\right)-\alpha_{\mathrm{DISORT}}\left(\lambda_{i}\right)\right)^{2}}$.

The band 3 (blue) is not used here because it revealed for being too much affected by atmospheric scattering.

2. Using the DISORT LUTs, the values of surface specific area (SSA) that minimise the spectral distance below are found

$d_{\mathrm{IR}}=\sqrt{\frac{1}{2} \sum_{i=5}^{6}\left(\alpha_{\mathrm{MODIS}}\left(\lambda_{i}\right)-\alpha_{\mathrm{DISORT}}\left(\lambda_{i}\right)\right)^{2}}$.

The band 7 is not used here since the signal is really low for these wavelengths.

3. The two spectral distances above are computed for each spectrum stored in both LUTs associated with snow and ice targets. The discrimination between snow and ice is inferred from the minimum of $d_{\mathrm{VIS} \text {, snow }}^{2}+d_{\mathrm{IR} \text {, snow }}^{2}$ and $d_{\mathrm{VIS}, \text { ice }}^{2}+d_{\mathrm{IR} \text {, ice }}^{2}$, which indicates the best matching spectrum.

4. Based on the best matching spectrum created with DISORT, the spectral albedo is known over the whole spectrum. It is then integrated with weights that correspond to the ground irradiance modelled by SPCTRAL2 (Bird and Riordan, 1986), thus yielding an estimate of the broadband albedo value.

This method allowed the contrasting optical properties of snow and ice to be accommodated. Indeed, the soot content mainly influences the albedo in the first part of the solar spectrum (up to around $1 \mu \mathrm{m}$ ), whereas the albedo in the second part of the solar spectrum is mainly influenced by the value of the SSA (Warren and Wiscombe, 1980). Since the penetration of light is generally decreasing as the wavelength increases, the SSA value retrieved in step 1 corresponds to a "mean" value for the first centimeters of the snowpack, whereas the SSA value retrieved in step 2 reflects more the conditions very close to the surface (Li et al., 2001). In the steps described above, either each band has the same weights (steps 1 and 2) or more weight is assigned to the IR bands (step 3). In the future, more advanced band weighting depending on the information content of each band (e. g. more weight for band 4 which is the most sensible to impurity to retrieve the impurity content) could be implemented as described in Somers et al. (2009).

As outlined above, the use of DISORT provides a means to compute the spectral albedo value of the snowpack from the SSA and soot content. The broadband albedo value corresponding to the actual ground irradiance (hereafter called 
Table 3. Description of the DISORT Look-Up-Tables used to infer SSA and soot content from spectral albedo values. The SSA range chosen for snow is the maximum range found in the literature (Domine et al., 2007). The soot content is based on the one described in Gardner and Sharp (2010). The parameters for ice were chosen so that the range of spectral albedo corresponds to the measured ice albedo range found in the literature (Gardner and Sharp, 2010).

\begin{tabular}{ll}
\hline Snow & \\
\hline$\theta$ & 0 to $88^{\circ}$ with $2^{\circ}$ sampling \\
SSA & 5 to $160 \mathrm{~m}^{2} \mathrm{~kg}^{-1}$ with $5 \mathrm{~m}^{2} \mathrm{~kg}^{-1}$ sampling \\
Soot content & $0,0.002,0.004,0.006,0.01,0.015,0.02,0.04$, \\
& $0.06,0.08,0.1,0.2,0.3,0.5,1,2 \mathrm{ng} \mathrm{g}^{-1}$ \\
\hline Ice & \\
\hline$\theta$ & 0 to $88^{\circ}$ with $2^{\circ}$ sampling \\
SSA & $5,10,15,20 \mathrm{~m}^{2} \mathrm{~kg}^{-1}$ \\
Soot content & 4 to $8 \mathrm{ng} \mathrm{g}^{-1}$ with $0.5 \mathrm{ng} \mathrm{g}^{-1}$ sampling, \\
& 9 to $19 \mathrm{ng} \mathrm{g}^{-1}$ with $0.5 \mathrm{ng} \mathrm{g}^{-1}$ sampling, \\
& 21,23 and $25 \mathrm{ng} \mathrm{g}^{-1}$ with $0.5 \mathrm{ng} \mathrm{g}^{-1}$ sampling \\
\hline
\end{tabular}

clear sky albedo) can thus be obtained. In addition, it becomes possible to estimate a value of the diffuse albedo (albedo of the same surface under diffuse illumination only). Such a diffuse albedo value is useful since it allows the evolution of the surface to be studied independently of the seasonal variations of the solar zenith angle. This diffuse albedo will be referred as white sky albedo in the following.

Alternative conversion methods have been tested to assess the relevance of the algorithm described above. Greuell and Oerlemans (2004) proposed two quadratic combinations of MODIS spectral bands 1, 2 and 4 to estimate the broadband albedo value. From their work we selected only Eq. (4) below as it proved to provide the best results in our case study:

$$
\begin{aligned}
& A_{V 1}=0.734 \alpha_{\text {MODIS }, 1}-0.717 \alpha_{\text {MODIS }, 1}^{2}+0.428 \alpha_{\text {MODIS }, 2} \\
& +0.458 \alpha_{\text {MODIS }, 4}^{2}+0.011 \alpha_{\text {MODIS }, 4} \ln \left(\frac{u}{u_{\text {ref }}}\right)
\end{aligned}
$$

where $u$ is the water column vapour and $u_{\text {ref }}$ its reference value. The former was estimated directly from the MODIS image as explained in Sirguey et al. (2009).

\section{Evaluation of the method and discussions}

The method described above has been applied to MODIS images acquired during summers 2008 and 2009. They were selected to match the dates when ground measurements were available and cloud cover was minimal.

\subsection{Accuracy assessment using field measurements}

Albedo values retrieved from MODIS level 1B images at the location of the AWS were compared to field measurements

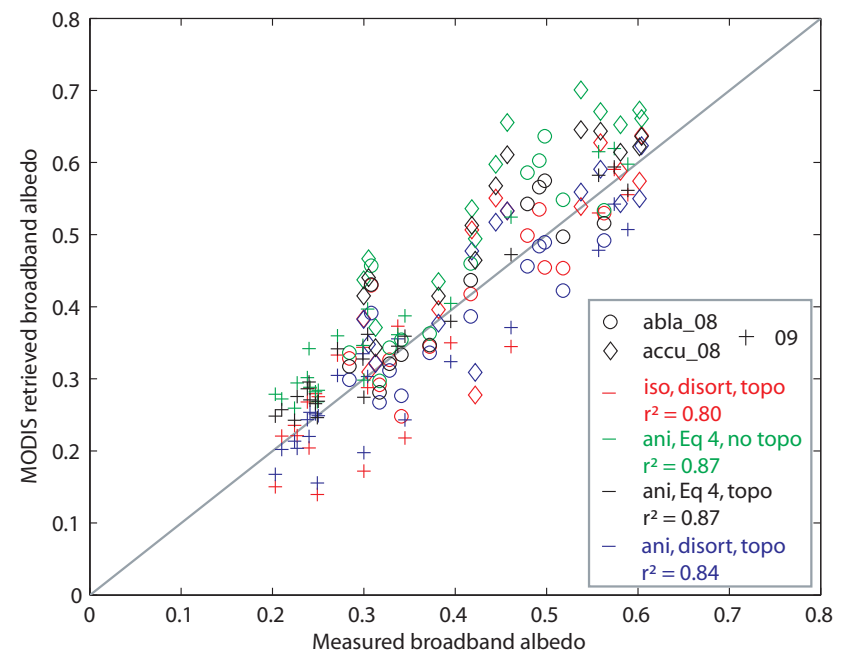

Fig. 2. Measured broadband albedo values versus MODIS retrieved albedo. The different symbols are for $1 /$ diamonds, accumulation zone, summer 2008, 2/circles, ablation zone, summer 2008 and $3 /$ crosses, ablation zone, summer 2009. The colours correspond to the method used to retrieve the albedo value and the determination coefficient, $r^{2}$, for each of the methods is also given in the legend of the figure. The $1: 1$ ratio line is indicated in grey.

in 2008 and 2009 under several scenarios. These scenarios come from different options at the different steps of the retrieval method: (i) assuming that snow and ice are lambertian or not lambertian surfaces (hereafter called "Iso" and "Ani", respectively); (ii) assuming that there is no terrain reflection or correcting from the terrain reflections (hereafter called "no topo" and "topo", respectively); and (iii) using Eq. (4) or DISORT LUTs for spectral conversion (hereafter called "Eq4" and "Disort", respectively). In addition, the albedo values provided by MOD10A1 products were also compared to field measurements.

Table 4 provides the statistics of the differences between the MODIS derived albedo based on the different methods and values measured at the AWSs. Figure 2 illustrates the dispersion between measured and MODIS-derived albedo values for the selected methods. From these results, the effect of the different hypotheses (e.g. lambertian vs. non lambertian surfaces, topographic vs. non topographic correction) on the retrieved albedo values can be characterised.

In every case, accounting for the anisotropy of the radiation reflected by snow provides better performance (i.e. ani versus iso in Table 4). This sole correction made the RMSD decrease by $10 \%$ all other things being equal. The correction of multiple reflections due to surrounding slopes (i.e. topo versus no topo in Table 4) also noticeably improved the retrieved value. The topographic correction appeared to have a greater impact under the Lambertian assumption (the RMSD improved $8.5 \%$ in the case of Eq. (4) and $19 \%$ in the case of DISORT). When accounting for the anisotropy of the reflected radiation, the topographic correction improved 
Table 4. Comparison between albedo values retrieved from MODIS and field measured albedo values for summers 2008 and 2009. In the methods, "Iso" means that snow and ice were considered as lambertian, whereas "Ani" means that an anisotropy correction was applied. "topo" vs "no topo" is relative to the correction of the multiples reflections due to surrounding slopes. "Eq4" is relative to the use of Eq. (4) for the narrow-to-broadband conversion, whereas "disort" refers to the method describes in Sect. 3.2.2. The statistics given in this table are $b$ for the mean difference between MODIS albedo values and the measured values, rmsd stands for the root mean square deviation between both values and $n$ is the mean absolute relative error in percent. The last two lines of the table indicate the number of pixels used in the statistics for MOD10A1 and for all the other methods based on MOD02. This number is lower for MOD10 since in many cases the glacier pixels were misclassified as land or cloud.

\begin{tabular}{|c|c|c|c|}
\hline Method & Summer 2008 & Summer 2009 & All \\
\hline Iso & $b=-0.085$ & -0.066 & -0.076 \\
\hline $\mathrm{Eq} 4$ & $\mathrm{rmsd}=0.145$ & 0.073 & 0.118 \\
\hline no topo & $n=28.0 \%$ & 23.6 & 29.4 \\
\hline Ani & -0.062 & -0.048 & -0.056 \\
\hline $\mathrm{Eq} 4$ & 0.130 & 0.056 & 0.103 \\
\hline no topo & 23.9 & 17.7 & 25.6 \\
\hline Iso & -0.035 & -0.039 & -0.037 \\
\hline $\mathrm{Eq} 4$ & 0.138 & 0.051 & 0.108 \\
\hline topo & 24.5 & 15.9 & 20.6 \\
\hline Ani & -0.017 & -0.024 & -0.020 \\
\hline $\mathrm{Eq} 4$ & 0.129 & 0.035 & 0.099 \\
\hline topo & 21.7 & 11.1 & 16.9 \\
\hline Iso & -0.017 & 0.018 & -0.000 \\
\hline Disort & 0.056 & 0.061 & 0.058 \\
\hline topo & 10.8 & 15.9 & 13.2 \\
\hline Ani & -0.000 & 0.030 & 0.014 \\
\hline Disort & 0.050 & 0.054 & 0.052 \\
\hline topo & 10.4 & 12.2 & 11.2 \\
\hline Iso & -0.055 & -0.006 & -0.03 \\
\hline Disort & 0.079 & 0.057 & 0.069 \\
\hline no topo & 15.7 & 16.5 & 16.1 \\
\hline Ani & -0.034 & 0.007 & -0.015 \\
\hline Disort & 0.063 & 0.041 & 0.054 \\
\hline no topo & 12.9 & 11.0 & 12.1 \\
\hline \multirow{3}{*}{ MOD10 } & 0.131 & 0.095 & 0.117 \\
\hline & 0.219 & 0.102 & 0.184 \\
\hline & 26.8 & 28.6 & 27.5 \\
\hline $\mathrm{N}, \bmod 10$ & 17 & 10 & 27 \\
\hline $\mathrm{N}, \bmod 02$ & 24 & 21 & 45 \\
\hline
\end{tabular}

the RMSD by $3.9 \%$ in the case of Eq. (4) and $3.8 \%$ using DISORT .

From Fig. 2, the coefficient of determination $r^{2}$ for each method is significant. It culminates for the methods us- ing Eq. (4), relying on spectral albedo being corrected for anisotropic reflectance. Ignoring the increased radiation due to the surrounding slopes introduced a positive bias since the retrieved radiance and in turn the corresponding albedo values are higher. Notwithstanding the better correlations obtained from Eq. (4), Table 4 reveals that these lesser dispersion in comparison with methods based on DISORT are obtained at the cost of a considerable loss of accuracy. Indeed, all other things being equal, the use of the DISORT-based method yielded a decrease of the RMSD by over $45 \%$.

Finally, the albedo provided in the MOD10 data product exhibited the largest RMSD value (Table 4). The positive bias of 0.117 although substantial could have been expected due to the type of albedo being retrieved in this global product. In considering the directional-hemispheric reflectance only, Klein and Stroeve (2002) ignored the additional diffuse radiation. The underestimation of irradiance logically results in an overestimation of the albedo value when compared to the bi-hemispherical albedo being measured at the AWS and used as a reference in this comparison.

From these results, the method based on DISORT and combining topographic and anisotropy corrections provided the better agreement with albedo values measured in the field. Therefore, this method was preferred and is the basis of all the results presented hereafter.

\subsection{Comparison between MODIS and terrestrial photographs albedo maps}

The maps of albedo retrieved from MODIS data were compared with the corresponding maps of albedo derived from terrestrial photographs (Dumont et al., 2011). This allowed the robustness and the spatial distribution of the computed broadband albedo to be evaluated. The original broadband albedo values from terrestrial photographs at a spatial resolution of $10 \mathrm{~m}$ were first interpolated to fill missing values and then re-sampled using a true mean at $250 \mathrm{~m}$. The terrestrial photographs having an accuracy on the albedo values estimated at $10 \%$ at $10 \mathrm{~m}$ spatial resolution, the accuracy of the maps resampled at $250 \mathrm{~m}$ is around $1 \%$. Thus, these maps provide an almost true reference to evaluated MODIS data.

Differences between maps of albedo derived from MODIS and terrestrial photographs are illustrated in Fig. 3 which presents for each $250 \mathrm{~m}$ pixel of the glacier the mean difference and the RMSD for 13 dates over the summers 2008 and 2009. The RMSD over Saint Sorlin Glacier is 0.088 , which is comparable to the accuracy of the albedo retrieved from terrestrial photographs (Dumont et al., 2011). In addition, the mean difference between MODIS and terrestrial photographs is 0.03 , demonstrating that the difference between the both datasets is barely biased.

However, those differences exhibit some spatial pattern worth discussing (Fig. 3). The differences between the albedo on MODIS and terrestrial photo maps are generally higher on the edges of the glacier than in the central parts 
(a) Pixel RMSD - MODIS vs photos
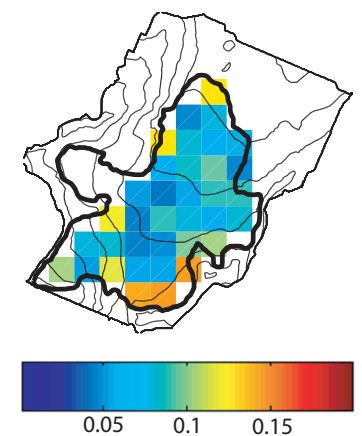

(b) Pixel mean difference - MODIS vs photos

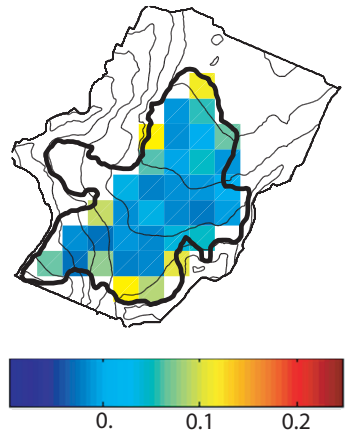

Fig. 3. Comparison between albedo retrieved from MODIS and terrestrial photographs. (a) RMSD for each pixel of the glacier for 13 epochs over summer 2008 and summer 2009. (b) Mean difference for each pixel for the same 13 epochs. RMSD and difference are indicated in albedo values. The contour of the glacier as it was measured in 2003 is also indicated with the thick black line on the two charts.

of the glacier. We believe that this may be due to artefacts associated with the spatial resolution of the DEMs used during the topographic correction. For the terrestrial photos, the original resolution was $10 \mathrm{~m}$, much finer than the $250 \mathrm{~m}$ pixel size obtained from MODIS images. In turn, a pixel of the DEM at $250 \mathrm{~m}$ fails to represent the spatial variability of the slope within its area $(6.25 \mathrm{ha})$ while the pixel of the $10 \mathrm{~m}$ DEM used for the topographic corrections in the method using terrestrial photographs achieves such representation down to 0.1 ha. In conjunction, the standard deviation of the slope is higher on the edges of the glacier than in the centre. As the slope has an influence on the amount of both reflected and incident radiation, depending on the illumination geometry (sun elevation, azimuth and terrain aspect), the loss of accuracy in the slope within a $250 \mathrm{~m}$ pixel propagates to the estimated albedo, thereby increasing its variance. Such variation being nonlinear with respect to the slope can explain that the mean slope is not adequate to yield a mean albedo, thus increasing the discrepancies on the edges, where the slope varies substantially. A second and not less significant explanation for the loss of accuracy close to the edges of the glacier may be that such pixels are often mixture of several materials (i.e. snow/ice and rock). For instance, at the end of the ablation season, the standard deviation of the albedo values derived from the photographs within each $250 \mathrm{~m}$ MODIS pixel at the edge of the glacier is typically twice larger at the edge of the glacier than the standard deviation computed from pixels in the central area (from 0.02 to 0.04). As the method presented to retrieve the albedo does not take into account the presence of rock, the accuracy of the method is expected to decrease when the glacier surface comprises an important debris cover. To address the problem of mixed pixels, it would be interesting to apply the albedo retrieval

method only to the part of the pixel reflectance which is attributed to snow and ice by the linear unmixing technique.

\subsection{Error sources}

\subsubsection{Cloud detection}

Before processing MODIS images, only those with a limited cloud cover were used. An automatic cloud detection based on MODIS reflective and emissive bands was implemented in the algorithm (Sirguey et al., 2009), before proceeding to the topographic correction of MODIS bands one to seven. Pixels identified as cloudy were not included in the computation of spectral albedos. In their visual inspection of MODIS images, Sirguey et al. (2009) reported that some problem of classifications sometimes happen between snow and clouds at the edges of the snow cover. The conclusion about the efficiency of the cloud detection method in the present study is the same.

\subsubsection{Atmospheric correction}

The atmospheric model used in this study is an adaptation of the single layer SPCTRAL2 model (Bird and Riordan, 1986), and is described in more details by Sirguey et al. (2009). To assess its performance at estimating the different irradiance contributions, Sirguey et al. (2009) conducted a thorough comparison with outputs from the more comprehensive $6 \mathrm{~S}$ model (Vermote et al., 1997). RMSEs were computed between the two datasets for direct and diffuse solar irradiance, diffuse environmental irradiance, and atmospheric intrinsic radiance. Discrepancies generally less than $10 \%$ compared to the output of the $6 \mathrm{~S}$ model in the seven MODIS spectral bands justified implementing the much simpler SPCTRAL2 model in this study. Further testing with data collected on Saint Sorlin Glacier confirmed the good agreement of this irradiance model (Dumont et al., 2011).

\subsubsection{Geolocation and gridding artefacts}

The albedo retrieved from MODIS images is sensitive to the good registration between the satellite image and the DEM. Aster DEM is known to have a $\pm 30 \mathrm{~m}$ planimetric accuracy (http://asterweb.jpl.nasa.gov/gdem.asp), while MODIS images are registered with a $\pm 50 \mathrm{~m}$ planimetric accuracy (Wolfe et al., 2002). To evaluate the impact of DEM and/or image misregistration on the retrieved albedo, the Aster DEM was translated horizontally by $100 \mathrm{~m}$. This yielded differences in the accumulation area up to RMSD $\leq 0.06$, where the albedo is higher and the terrain is more rugged. In the ablation area, where the slope is less variable and ice replaces snow during the summer, values are less sensitive to the misregistration $(\mathrm{RMSD}<0.03)$. This stresses the fact that the albedo retrieval method remains substantially sensitive to misregistration between the image and the DEM especially where the slope is important and/or in highly irregular 
terrain. In addition to the geolocation error, MODIS data are subject to mismatch between the location on the ground from which MODIS observations are derived and the predefined grid cells used for storing observations (Tan et al., 2006). This pixel shift is particularly problematic at high view zenith angles (at the edge of the scan line) for example and can also affect the retrieval especially in highly irregular terrain.

\subsubsection{On the grain size retrieval and the anisotropy correction}

The anisotropy correction used in this work remains based on measurements and does not take into account variations of anisotropy factors due to grains size and shape. More sophisticated models accounting for the shape of grains (Zege et al., 2011) have been used for snow grain size, impurity content, and albedo retrieval. Nevertheless, it was believed unnecessary to implement a more comprehensive anisotropy correction because: (i) due to the accuracy of our method, considering the shape of the grains would not bring significant improvements; and (ii) despite the effect of surface roughness on the albedo (Hudson and Warren, 2007; Zhuravlela and Kokhanovsky, 2011), this parameter is ignored by Zege et al. (2011). The fact that the surface roughness generally produces opposite anisotropic effects compared to smooth ice or snow surfaces (Hudson and Warren, 2007) may explain why the benefit of the anisotropy correction was of lower magnitude than that attributed to the topographical correction. Indeed, the BRDF associated with the surface considered at the granular scale can depart significantly from that of the surface observed at a macroscopic scale and affected by the surface roughness. Accounting for this departure could further improve the impact of the anisotropy correction (e.g. Li and Strahler, 1985).

\section{Application to Saint Sorlin Glacier from 2000 to 2009}

Ten years (2000-2009) of MODIS data have been processed on Saint Sorlin Glacier using the algorithm presented and assessed in the previous sections, namely using topographic and anisotropy corrections and DISORT. Cloud-free images were selected over the period from May to October in order to cover the whole ablation period. This represents a total of 405 maps of albedo over ten years.

Figure 4 shows an example of albedo map obtained on 16 July 2007. All the coloured pixels are the ones used hereafter for computing the average glacier albedo. Values of the pixel indicated by a cross in Fig. 4 were used to monitor the albedo relative to the ablation zone.

\subsection{The albedo of the ablation zone}

Figure 5 shows the evolution of surface albedo for the pixel in the centre of the ablation zone of the glacier represented with a plus on Fig. 4, from July to mid-September, when

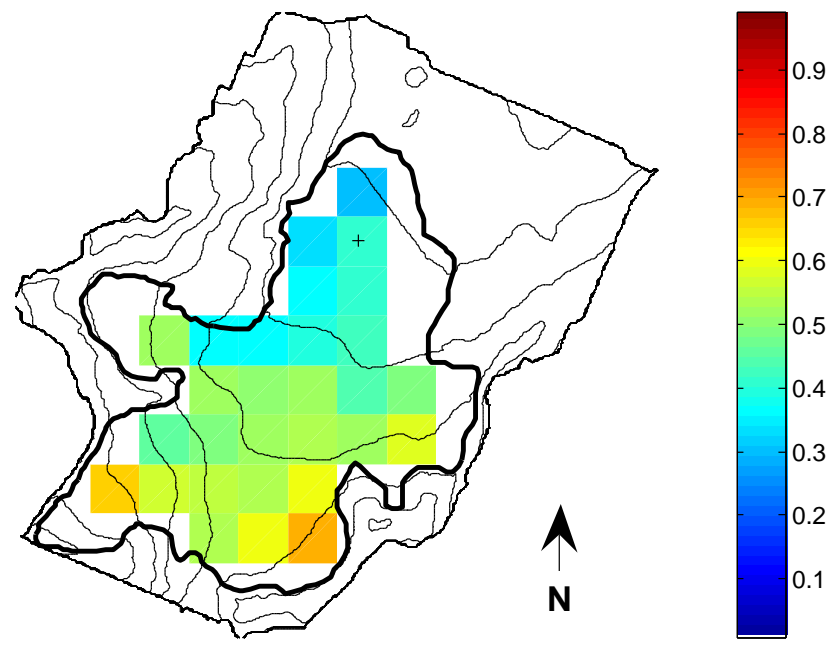

Fig. 4. Clear sky albedo retrieved from MODIS on 16 July 2007. This map has been retrieved using anisotropic/topographic corrections and DISORT. The pixel indicated by the plus is the pixel used for the monitoring of the albedo in the ablation zone. All the coloured pixels are used to compute the mean albedo of the glacier.

the glacier surface is generally comprised of bare ice. The albedo presented here is the white sky albedo as explained in Sect. 3.2.2. Consequently, this albedo is not affected by the illumination conditions and only reflects the evolution of the surface. Since maps of albedo are produced on an irregular temporal basis resulting from possible cloud cover, averaging maps over time makes little physical sense. In addition, to grasp the evolution of the albedo of ice, the effect of snowfall during the period must be avoid. Figure 5 therefore plots the minimum value of the albedo for a ten-day moving window calculated every fifth day.

Figure 5 suggests that there was no obvious trend of decrease in the typical albedo of ice during this decade. This was similar for all other pixels of the ablation zone. This contrasts with a study on Morteratsch Glacier (Swiss Alps) whereby Oerlemans et al. (2009) reported a decrease in the albedo of ice from 0.32 to 0.15 over the period 2001 to 2006 . This decrease was believed to be caused by an enhanced deposition of dust from lateral moraines on the glacier surface. In this context, the topography of the ablation zone of Saint Sorlin glacier is different as the terminus is quite wide regarding to the length of the glacier, and lateral moraines are smaller compared to those of the Morteratsch Glacier. This difference could explain the contrasting trends in the evolution of the albedo for both glaciers.

\subsection{Albedo and mass balance}

We now consider the evolution of the albedo averaged over the whole glacier surface. The pixels chosen for averaging are coloured in Fig. 4 and entirely included within the glacier 


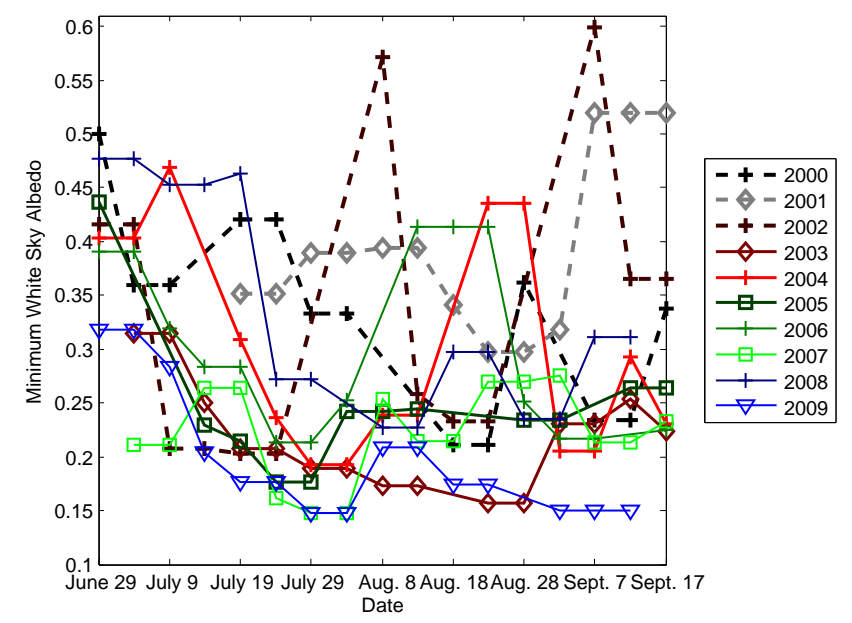

Fig. 5. Minimum white sky albedo retrieved from MODIS data in the ablation zone for summers 2000-2009. This figure shows the evolution of the minimum albedo of one pixel of the ablation zone, the crossed pixel in Fig. 4. It shows minimum value of albedo over 10 days each 5 days.

outlines, 29 pixels in total. Potentially mixed pixels on the right hand side of the ablation zone were ignored to reduce biases. In this section, only images for which none of the selected pixels were cloudy were considered.

Figure 6a shows the measured annual mass balance versus of the annual minimum value of this mean surface albedo (clear sky and white sky) for each year of the 2000-2009 period. The annual mass balance values were obtained from field measurements and are reported with a RMSD of $200 \mathrm{~kg} \mathrm{~m}^{-2}$ (Cogley and Adams, 1998). The RMSD of the mean albedo values, computed as $0.052 / \sqrt{29}$, are also indicated in Fig. 6a as error bars. The red crosses are for the clear sky albedo value, whereas the blue diamonds are for the white sky albedo. The coefficient of determination between the albedo and the mass balance is $91.6 \%$ for the clear sky albedo and $94.6 \%$ for the white sky albedo. When disregarding the year 2001, the only positive mass balance value, the coefficient of determination is $89.3 \%$ for the clear sky albedo and $89.6 \%$ for the white sky albedo. The minimum albedo for year 2002 is the one with the poorest fit to the regression line calculated using the method from York et al. (2004), i.e. taking into account the error for each variable

Figure $6 \mathrm{~b}$ also illustrates a significant and strong anticorrelation between the annual mass balance and the ELA (Rabatel et al., 2005). To facilitate the identification of the ELA on Landsat and SPOT satellite images, a spectral bands combination has been used (5, 4, 2 for Landsat and 4, 3, 1 for SPOT). Then, the ELA has been delineated manually and its average altitude computed using the ASTER DEM. The error on the ELA calculation results from the accuracy of the DEM, the pixel size of the images (ranging between 10 and $30 \mathrm{~m}$ ), the slope of the glacier at the level of the ELA, and the standard deviation of the calculation of the average
ELA along its delineation. The latter is the most important contributor. The RMSD for the ELA and the mass balance are reported on the graph. The coefficient of determination between the ELA and the mass balance is $94.7 \%$. All the correlation coefficients in Fig. 6 are significant at the $95 \%$ confidence level.

The strong correlation shown in Fig. 6 is physically based. Indeed, the date of the minimum albedo matches the date when the snow line has reached its uppermost position and so to the date when the snow line can be considered as a good indicator of the equilibrium line (Rabatel et al., 2005, 2008). For each year, this date ranges between mid-August and midSeptember. At this date the mean albedo of the glacier is then representative of the relative share of areas between the ablation zone (made of ice) and the accumulation zone (covered with snow). The best correlation is obtained for the white sky albedo which confirms our choice to use this variable instead of the clear sky albedo to monitor the glacier surface conditions. The departure of year 2002 from the regression line may be explained by the snowy end of the summer on this year. Indeed as shown in Fig. 4, the albedo of the ablation zone reaches minimum values higher than 0.5 in August. This indicates that there were several periods of snowy weather. Most of the MODIS data from this period were not usable due to clouds. This may also have prevented satellite observation to be obtained for the day where the snow line is the highest. This illustrates one of the limitations of the methods which is inherent to the use of visible images.

While the correlation obtained between the albedo and the mass balance compares to that with the ELA, we believe that the albedo contains more information about the surface of the glacier than the ELA does. In addition, the configuration of the glacier, with several orientations in the accumulation zone may complicate the determination of the mean ELA.

These results further stress the significance of the albedo on the mass balance of this kind of alpine glaciers (Dumont et al., 2012). The strong linear correlation shown in Fig. 6 proves that mass balance variations may be inferred from the minimum albedo of the glacier during the ablation season. This hypothesis would however benefit from being tested on several glaciers under different climates and this work should be pursued in this direction. The method proposed here for retrieving interannual variations of mass balance is comparable to the study made by Greuell et al. (2007) on the Svalbard glaciers and on the method proposed by Rabatel et al. (2005, 2008) to retrieve the mass balance variations from the ELA.

\section{Conclusions}

This study presents a new method to retrieve glacier broadband albedo from MODIS images at $250 \mathrm{~m}$ resolution under clear-sky conditions based on previous work of Sirguey et al. (2009) and Dumont et al. (2011). Broadband albedo over the entire solar spectrum is computed by 
(a)

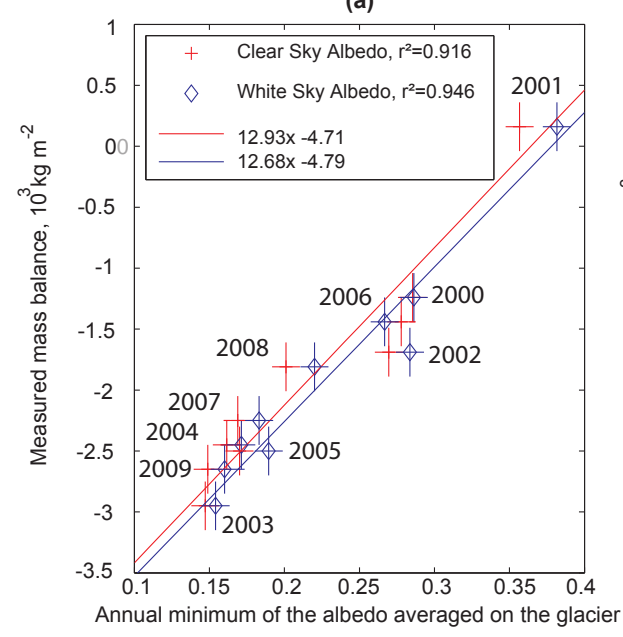

(b)

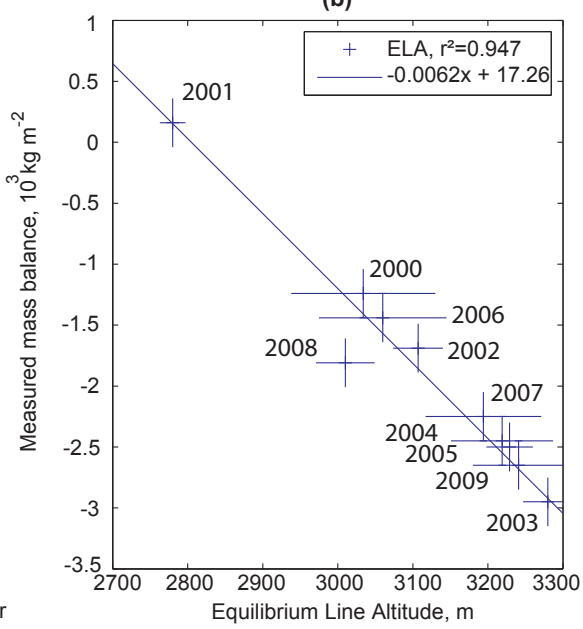

Fig. 6. Measured annual mass balance versus (a) the minimum of the mean glacier albedo and (b) the equilibrium line altitude for years 2000 to 2009. The RMSDs associated with each data points, the coefficients of determination $r^{2}$ and the regression lines calculated with the method described in York et al. (2004) are indicated on the charts. On the left panel the clear sky albedo is plotted in red crosses, whereas the white sky albedo is the blue diamonds.

taking into account rugged topography, as well as snow and ice anisotropy. The narrow-to-broadband conversion is performed by minimizing the distance to spectral forms computed by the DISORT radiative model and is shown to be more efficient than other existing equations (Greuell and Oerlemans, 2004). RMSD between measured and MODIS retrieved albedo is \pm 0.052 or about $10 \%$ relative error. In comparison, the RMSD found for the MOD10 snow albedo product is about three times higher. Comparison between MODIS and terrestrial photographs albedo maps also revealed a good temporal consistence between the two datasets. The main source of errors may stem from a misregistration between the satellite image and the DEM used for topographic correction, the presence of mixed pixels (including ice/snow and rocks/debris), and/or the presence of undetected clouds.

This method has been applied over ten years of MODIS data (2000-2009) on Saint Sorlin Glacier. No obvious decreasing trend could be detected relative to the typical summer surface albedo in the ablation zone. This contrasts with results reported by Oerlemans et al. (2009) on Morteratsch Glacier whereby the surface albedo exhibited a significant decrease over the period 2001-2006. In addition, the annual mass balance of Saint Sorlin Glacier was compared with the minimum albedo value (spatial averaged over the whole glacier) observed with MODIS during the ablation season. A strong linear correlation exists between the two variables. Furthermore, the period when the albedo reaches a minimum over the glacier closely corresponds to the time at which the snow line is found to be at its highest elevation and is thus considered as a good indicator of the glacier equilibrium line. This suggests that the strong correlation can be explained by the fact that this minimal albedo contains a high degree of information regarding the relative share of areal surfaces be- tween the ablation zone (i.e. bare ice with a generally lower albedo) and the accumulation zone (i.e. snow covered with a relatively high albedo).

This work has to be extended to other glaciers and climates and it could therefore be of great use to monitor and understand the energy balance of several glaciers over the ablation season and its sensitivity to climate change. One of the limitations of the method is that it may not work on debris covered glaciers, at least to compute the mass balance of glaciers with a debris-covered terminus. The high linear correlation between the minimum albedo and the annual mass balance can be used to retrieve interannual variations of the glacier mass balance. Many other possible uses of these albedo maps exist. For instance they can be useful to investigate the midterm temporal trends of the glacier albedo in relationship with climate trends or for the assimilation of albedo values in surface energy balance models to improve the simulation of spatially distributed glacier mass balance (Dumont et al., 2012).

Acknowledgements. The authors are grateful to the French observatory GLACIOCLIM and to all the people who helped with the AWS for the measurements on Saint Sorlin glacier. They also want to acknowledge the project LEFE ADAC of French institute INSU that have funded this work. We thank USGS-EDC for allowing us free access to Landsat images. SPOT images were provided through the CNES/SPOT-Image ISIS program, contracts 405 and 435. The authors are grateful to the two reviewers, S. Lhermitte and J. Dozier, for providing in-depth review of the paper.

Edited by: A. Klein 


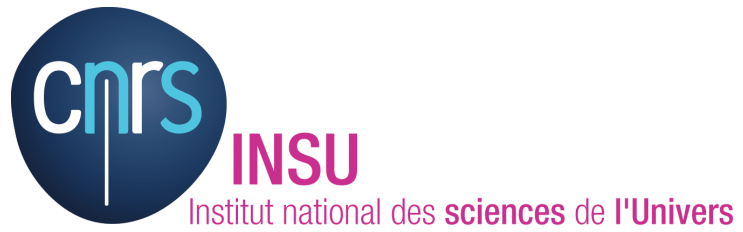

The publication of this article is financed by CNRS-INSU.

\section{References}

Bird, R. and Riordan, C.: Simple solar model for direct and diffuse irradiance on horizontal and titled planes at the earth's surface for a cloudless atmosphere, J. Clim. Appl. Meteorol., 25, 87-97, 1986.

Cogley, J. G. and Adams, W. P.: Mass balance of glaciers other than ice sheets, J. Glaciol., 44, 315-325, 1998.

Domine, F., Taillandier, A.-S., and Simpson, W. R.: A parameterization of the specific surface area of seasonal snow for field use and for models of snowpack evolution, J. Geophys. Res., 112, F02031, doi:10.1029/2006JF000512, 2007.

Dozier, J., Green, R., Nolin, A., and Painter, T.: Interpretation of snow properties from imaging spectrometry, Remote Sens. Environ., 113, 25-37, doi:10.1016/j.rse.2007.07.029, 2009.

Dumont, M., Brissaud, O., Picard, G., Schmitt, B., Gallet, J.-C., and Arnaud, Y.: High-accuracy measurements of snow Bidirectional Reflectance Distribution Function at visible and NIR wavelengths - comparison with modelling results, Atmos. Chem. Phys., 10, 2507-2520, doi:10.5194/acp-10-2507-2010, 2010.

Dumont, M., Sirguey, P., Arnaud, Y., and Six, D.: Monitoring spatial and temporal variations of surface albedo on Saint Sorlin Glacier (French Alps) using terrestrial photography, The Cryosphere, 5, 759-771, doi:10.5194/tc-5-759-2011, 2011.

Dumont, M., Durand, Y., Arnaud, Y., and Six, D.: Variational assimilation of albedo in a snowpack model and reconstruction of the spatial mass-balance distribution of an alpine glacier, J. Glaciol., 58, 151-164, doi:10.3189/2012JoG11J163, 2012.

Gardner, A. S. and Sharp, M. J.: A review of snow and ice albedo and the development of a new physically based broadband albedo parameterization, J. Geophys. Res., 115, F01009, doi:10.1029/2009JF001444, 2010.

Greuell, W. and Oerlemans, J.: Narrow-to-broadband conversion for glacier ice and snow: equations based on modeling and ranges of validity of the equations, Remote Sens. Environ., 89, 95-105, doi:10.1016/j.rse.2003.10.010, 2004.

Greuell, W., Kohler, J., Obleitner, F., Glowacki, P., Melvold, K., Bernsen, E., and Oerlemans, J.: Assessment of interannual variations in the surface mass balance of 18 Svalbard glaciers from the Moderate Resolution Imaging Spectroradiometer/Terra albedo product, J. Geophys. Res.-Atmos., 112, D07105, doi:10.1029/2006JD007245, 2007.

Hall, D. K., Riggs, G. A., and Salomonson, V. V.: MODIS/Aqua Snow Cover Daily L3 Global 500 m Grid V005, version 5, 2008, 2009, National Snow and Ice Data Center, Boulder, Colorado, USA, Digital media, 2007 (updated daily).

Hock, R.: Glacier melt: a review of processes and their modelling, Prog. Phys. Geog., 29, 362-391, doi:10.1191/0309133305pp453ra, 2005.
Hudson, S. R. and Warren, S. G.: An explanation for the effect of clouds over snow on the top-of-atmosphere bidirectional reflectance, J. Geophys. Res.-Atmos., 112, D19202, doi:10.1029/2007JD008541, 2007.

Kipp and Zonen: Instruction Manuel CNR1 Net radiometer, Kipp and Zonen, Dellft, The Netherlands, 2 pp., 2009.

Klein, A. G. and Stroeve, J.: Development and validation of a snow albedo algorithm for the MODIS instrument, Ann. Glaciol., 34, 45-52, 2002.

Klok, E., Greuell, W., and Oerlemans, J.: Temporal and spatial variation of the surface albedo of Morteratschgletsher, Switzerland, as derived from 12 Landsat images, J. Glaciol., 49, 491-502, 2003.

Knap, W., Brock, B., Oerlemans, J., and Willis, I.: Comparison of Landsat TM-derived and ground-based albedos of Haut Glacier d'Arolla, Switzerland, Int. J. Remote Sens., 20, 3293-3310, 1999a.

Knap, W., Reijmer, C., and Oerlemans, J.: Narrowband to broadband conversion of Landsat TM glacier albedos, Int. J. Remote Sens., 20, 2091-2110, 1999b.

Li, W., Li, X., and Strahler, A. H.: Geometric-optical mapping of a conifer forest canopy, IEEE T. Geosci. Remote, 23, 705-721, doi:10.1109/TGRS.1985.289389, 1985.

Li, W., Stamnes, K., Chen, B., and Xiong, X.: Snow grain size retrieved from near-infrared radiances at multiple wavelengths, Geophys. Res. Lett., 28, 1699-1702, doi:10.1029/2000GL011641, 2001.

Liang, S., Stroeve, J., and Box, J.: Mapping daily snow/ice shortwave broadband albedo for Moderate Resolution Imaging Spectroradiometer (MODIS): the improved direct retrieval algorithm and validation with Greenland in situ measurements, J. Geophys. Res., 110, D10109, doi:10.1029/2004JD005493, 2005.

Lyapustin, A., Tedesco, M., Wang, Y., Aoki, T., Hori, M., and Kokhanovsky, A.: Retrieval of snow grain size over Greenland from MODIS, Remote Sens. Environ., 113, 2463-2475, doi:10.1016/j.rse.2009.05.008, 2009.

Oerlemans, J., Giesen, R., and Van den Broeke, M. R.: Retreating alpine glaciers: increased melt rates due to accumulation of dust (Vadret de Morteratsch, Switzerland), J. Glaciol., 55, 729-736, 2009.

Painter, T., Rittger, K., McKenzie, C., Slaughter, P., Davis, R., and Dozier, J.: Retrieval of subpixel snow covered area, grain size, and albedo from MODIS, Remote Sens. Environ., 113, 868-879, doi:10.1016/j.rse.2009.01.001, 2009.

Rabatel, A., Dedieu, J.-P., and Vincent, C.: Using remote-sensing data to determine equilibrium-line altitude and mass-balance time series: validation on three French glaciers, 1994-2002, J. Glaciol., 51, 539-546, doi:10.3189/172756505781829106, 2005.

Rabatel, A., Dedieu, J.-P., Thibert, E., Letreguilly, A., and Vincent, C.: 25 years (1981-2005) of equilibrium-line altitude and mass balance reconstruction on Glacier Blanc, French Alps, using remote sensing methods and meteorological data, J. Glaciol., 54, 307-314, 2008.

Schaepman-Strub, G., Schaepman, M., Painter, T., Dangel, S., and Martonchik, J.: Reflectance quantities in optical remote sensing definitions and case studies, Remote Sens. Environ., 103, 27-42, doi:10.1016/j.rse.2006.03.002, 2006. 
Somers, B., Delalieux, S., Stuckens, J., Verstraeten, W. W., and Copping, P: A weigthed linear spectral mixture analysis approach to address endmember variability in agricultural productions system, Int. J. Rem. Sens., 30,139-147, doi:10.1080/01431160802304625, 2009.

Sicart, J.-E., Hock, R., and Six, D.: Glacier melt, air temperature, and energy balance in different climates: the Bolivian Tropics, the French Alps, and Northern Sweden, J. Geophys. Res., 113, D24113, doi:10.1029/2008JD010406, 2008.

Sirguey, P.: Simple correction for multiple reflection in rugged terrain, Int. J. Remote Sens., 30, 1075-1081, 2009.

Sirguey, P., Mathieu, R., Arnaud, Y., Khan, M., and Chanussot, J.: Improving MODIS spatial resolution for snow mapping using wavelet fusion and ARSIS concept, IEEE T. Geosci. Remote, 32, 78-82, 2008.

Sirguey, P., Mathieu, R., and Arnaud, Y.: Subpixel monitoring of the seasonal snow cover with MODIS at $250 \mathrm{~m}$ spatial resolution in the Southern Alps of New Zealand: methodology and accuracy assessment, Remote Sens. Environ., 113, 160-181, doi:10.1016/j.rse.2008.09.008, 2009.

Six, D., Wagnon, P., Sicart, J., and Vincent, C.: Meteorological controls on snow and ice ablation for two very contrasted months on Saint-Sorlin Glacier (France), Ann. Glaciol., 50, 66-72, 2009.

Stamnes, K., Tsay, S. C., Wiscombe, W. J., and Jayaweera, K.: Numerically stable algorithm for discrete-ordinate-method radiative transfer in multiple scattering and emitting layered media, Appl. Optics, 27, 2502-2509, 1988.

Stroeve, J., Box, J., and Haran, T.: Evaluation of the MODIS (MOD10A1) daily snow albedo product over the Greenland ice sheet, Remote Sens. Environ., 105, 155-171, doi:10.1016/j.rse.2006.06.009, 2006.

Tan, B., Woodcock, C. E., Hu, J., Zhang, P., Ozdogan, M., Huang, W., Yang, W., Kyazikhin, Y., and Myneni, R. B.: The impact of gridding artifacts on the local spatial properties of MODIS data: Implications for validation, compositing, and band-to-band registration across resolutions, Remote Sens. Environ., 105, 98-114, doi:10.1016/j.rse.2006.06.008, 2006.
Tedesco, M. and Kokhanovsky, A. A.: The semi-analytical snow retrieval algorithm and its application to MODIS data, Remote Sens. Environ., 111, 228-241, doi:10.1016/j.rse.2007.02.036, 2007.

York, D., Evensen, N. M., Martinez, M. L., and Delgado, J.: Unified equations for the slope, intercept, and standard errors of the best straight line, Am. J. Phys., 72, 367-375, doi:10.1119/1.1632486, 2004.

Vermote, E., Tanre, D., Deuze, J.-L., Herman, M., and Morcette, J.J.: Second simulation of the satellite signal in the solar spectrum, 6S: an overview, IEEE Geosci. Remote, 35, 675-686, 1997.

Vincent, C.: Influence of climate change over the 20th century on four French glacier mass balance, J. Geophys. Res., 107, D194375, doi:10.1029/2001JD000832, 2002.

Warren, S. G.: Optical properties of snow, Rev. Geophys., 20, 6789, 1982.

Warren, S. G. and Wiscombe, W. J.: A model for the spectral albedo of snow: II. snow containing atmospheric aerosols, J. Atmos. Sci., 37, 2734-2745, 1980.

Wolfe, R., Nishihama, M., Flieg, A., Kuyper, J., Roy, D., Storey, J., and Patt, F.: Achieving sub-pixel geolocation accuracy in support of MODIS land science, Remote Sens. Environ., 83, 31-49, doi:10.1016/S0034-4257(02)00085-8, 2002.

Zege, E. P., Katsev, I. L., Malinka, A. V., Prikhach, A. S., Heygster, G., and Wiebe, H.: Algorithm for retrieval of the effective snow grain size and pollution amount from satellite measurements, Remote Sens. Environ., 115, 2647-2685, doi:10.1016/j.rse.2011.06.001, 2011.

Zhao, S., Cheng, W., Zhou, C., Chen, X., Zhang, S., Zhou, Z., Liu, H., and Chai, H.: Accuracy assessment of the ASTER GDEM and SRTM3 DEM: an example in the Loess Plateau and North China Plain of China, Int. Jour. Rem. Sens., 32, 80818093, doi:10.1080/01431161.2010.532176, 2011.

Zhuravlela, T. B. and Kokhanovsky, A. A.:Influence of surface roughness on the reflective properties of snow, J. Quant. Spectrosc. Ra., 112, 1353-1368, doi:10.1016/j.jqsrt.2011.01.004, 2011. 